\title{
ANALYSIS OF THE PHTHALATE CONTENT LEVELS IN WINE PRODUCTS
}

\author{
Duca Gheorghe ${ }^{1}$, Sturza Rodica², Gaina Boris ${ }^{1}$, Lazacovici Dmitri² * \\ ${ }^{1}$ Academy of Sciences of Moldova, Chisinau, Republic of Moldova \\ ${ }^{2}$ National Center for Quality Testing of the Alcoholic Beverages \\ Chisinau, Republic of Moldova \\ *dirigiblesina@yahoo.com
}

\begin{abstract}
The health of the nation is one of the most important concerns of governmental and nongovernmental organizations, ecologists, etc. A number of studies have shown phthalates' potential impact on human health due to their carcinogenic and endocrine-disrupting effects [1]. More than 2000 analyses for determination of phthalates' rests in alcoholic beverages were done in the laboratory of National Center for Quality Testing of the Alcoholic Beverages (Republic of Moldova) using modern method of analysis like GC-MS.
\end{abstract}

Keywords: phthalates, wine, gas-chromatography, mass-spectrometry, dibutylphthalate.

\section{Introduction}

Today, in modern, industrialized society people can hardly imagine life without home appliances, communication systems, a convenient plastic packaging, fragrance and cosmetics. Most of these and many other chemical products have their properties such as strength, ductility, durability, incombustibility (incombustibility), etc., owing to a number of synthetic organic chemicals. Phthalates are among the members of this series. Phthalates (esters of phthalic acid) are included in the compositions of almost all types of plastics, rubber, paints and varnishes, giving them elasticity and strength. The most of the phthalates produced used exactly as plasticizers, near 90\% (table 1). At perfume and cosmetic products phthalates mainly act as solvents and flavor fixatives.

Table 1

Annual production and consumption of wide-spread phthalates in EU countries.

\begin{tabular}{|l|c|c|c|}
\hline \multicolumn{1}{|c|}{ Phthalate } & Abbreviation & Annual production & Annual consumption \\
\hline Dimethylphthalate & DMP & - & $10000-20000^{5}$ \\
\hline Diethylphthalate & DEP & - & $10000-20000^{5}$ \\
\hline Dibutylphthalate & DBP & $26000^{1}$ & $18000^{1}$ \\
\hline Benzylbutylphthalate & BBP & $45000^{2}$ & $19500^{4}$ \\
\hline Bis(2-ethylhexyl)phthalate & DEHP & $595000^{3}$ & $476000^{3}$ \\
\hline
\end{tabular}

${ }^{1}$ : EU RA DBP 2004; ' : EU RA BBP 2004; ${ }^{3}$ : EU RA DEHP 2001; ${ }^{4}$ : EU RA BBP 2007; 5 Harris et al., 1997

The annual production of phthalates was estimated by the World Health Organization (WHO) to approach 8 million pounds (by data on 1992) [2], and 5 billion tons (by data on January 2011) [3]. Approximately 95\% of the phthalate enters into the production of polymeric materials, in some of them phthalates' content reaches $50 \%$ by weight of the polymer.

Humans always are surrounded by materials containing phthalates, such as linoleum, insulation of wires, pipes, plastic housings of domestic appliances, toys, varnishes and paints.

Most researchers from different organizations suggest that in most cases influence of phthalates upon person is below the tolerable daily intakes (TDI) [2, 4-8]. But it is difficult to determine accurately the dose of exposure as the spreading of phthalates everywhere. According to international studies performed by Center for the Evaluation of Risks to Human Reproduction [7] this factor is in the following ranges (table 2). Women and children are most susceptible to phthalates.

Table 2

Daily dose of phthalate and its effect on different categories of the population

\begin{tabular}{|c|c|c|c|c|c|}
\hline \multirow[b]{2}{*}{$\begin{array}{c}\text { Category/ } \\
\text { Age }\end{array}$} & \multicolumn{5}{|c|}{ Age categories } \\
\hline & $\begin{array}{c}\text { Childrens } \\
0-1\end{array}$ & $\begin{array}{c}\text { Childrens } \\
1-3\end{array}$ & $\begin{array}{c}\text { Childrens } \\
\text { 4- } 10\end{array}$ & $\begin{array}{c}\text { Women } \\
\text { 18- } 20\end{array}$ & $\begin{array}{c}\text { Men } \\
\text { 18- } 80\end{array}$ \\
\hline $\begin{array}{l}\text { Daily intakes, } \\
\mu \mathrm{g} / \mathrm{kg} \mathrm{BW}\end{array}$ & $55-380$ & $20-183$ & $5-54$ & $8-124$ & $8-92$ \\
\hline
\end{tabular}

$(B W-b o d y$ weight $)$ 
It is supposed that phthalates accumulate in the human body, which negatively affects its hormones, liver and kidneys may also become the causes of allergies, asthma and cancer, neurodevelopmental disorders and abnormalities in the development of children [8-12]. Molecules of phthalates are not structural elements of the polymer chains and therefore easily stand out in the environment, getting into the human body through food, skin or by inhalation.

In a number of investigated wine-products released by vendors it was detected the presence of phthalates. Particular attention was given to the DBP.

\section{Material and Methods}

\subsection{Methods and reagents}

Measuring the concentration of dibutyl phthalate in wine and base-wine based on its elimination by chloroform extraction, chromatographic separation on a capillary column, identify the retention time and mass spectrum, and quantify with the characteristic ion $\mathrm{m} / \mathrm{z}$ 149. Measuring the concentration of dibutylphthalate in alcoholic beverages such as vodka, brandy, cognac alcohol, rectified ethyl alcohol was based on chromatographic separation of the sample on a capillary column using Aldrin with a purity above $99.3 \%$ and supplied by SUPELCO as an internal standard, the identification was made by retention times and mass spectrum, quantification of characteristic ion m/z 149 for DBP, and $66,261,263,265$ for Aldrin.

The background solution (synthetic wine) was used to prepare the calibration solutions. It consisted of aqueous solution of $15 \%$ ethanol and tartaric acid $\left(5 \mathrm{~g} / \mathrm{dm}^{3}\right)$ (tartaric acid, supplied by FLUKA, puriss. p.a. for ion chromatography) and carried to the $\mathrm{pH}$ to 3.5 with $5 \mathrm{M}$ sodium hydroxide. Synthetic wine was used for calibration standard solutions with concentrations of DBP: 0 - 1,00 mg/dm³ (dibutylphthalate, PESTANAL from SIGMA-ALDRICH, 99.8\%). For the extraction of DBP, $100 \mathrm{ml}$ of sample (calibration solution) was placed in a separatoring funnel of $250 \mathrm{~cm}^{3}$ with addition of $10 \mathrm{~cm}^{3}$ of chloroform (Chloroform, LGC PROMOCHEM, for HPLC). Extraction was implemented in 10 min with continuous shaking. After separating the organic layer the bottom layer of chloroform was drained through a paper filter with anhydrous sodium sulfate (sodium sulfate anhydrous, STANCHEM, Spain). Collected $10 \mathrm{ml}$ of the chloroform extract was transferred into a gas chromatography vial, from which was selected 1,0 $\mu$ l of extract by microsyringe directly for analysis using gas chromatography with mass-spectrometer.

\subsection{Instruments}

SHIMADZU GCMS-QP-2010S (IS) with a COMBI PAL autosampler (CTCANALYTICS, Zwingen, Switzerland) equipped with fused silica column RESTEK - Rtx-5MS $(30 \mathrm{~m} / 0.25 \mathrm{~mm} / 0.25 \mu \mathrm{m} 100 \%$ dimethylpolisiloxane phase) was used to perform injections and gas chromatographic analyses in an automated way.

\subsection{Gas chromatography - mass spectrometry}

The oven program started at an initial temperature of $150^{\circ} \mathrm{C}$ for $1 \mathrm{~min}$. Temperature was then increased at a rate of $10^{\circ} \mathrm{C} / \mathrm{min}$ to $200^{\circ} \mathrm{C}$, maintained for $1 \mathrm{~min}$, then increased at a rate of $20^{\circ} \mathrm{C} / \mathrm{min}$ to $280^{\circ} \mathrm{C}$ and maintained for $10 \mathrm{~min}$. The carrier gas was helium at $1.0 \mathrm{ml} / \mathrm{min}(99.9990 \%)$, split 5. Ionisation was performed by electron impact (EI), setting the electron multiplier to $1300 \mathrm{~V}$. The temperatures used were $260^{\circ} \mathrm{C}$ for the injector, $280^{\circ} \mathrm{C}$ for the transfer line, and $200^{\circ} \mathrm{C}$ for the ion source. The compounds were quantified in selected ion monitoring (SIM) mode. The analyte to internal standard peak area ratio was used as analytical signal for constructing the calibration graphs.

Duration of gas chromatography-mass spectrometric analysis for phthalates constituted 25 minutes.

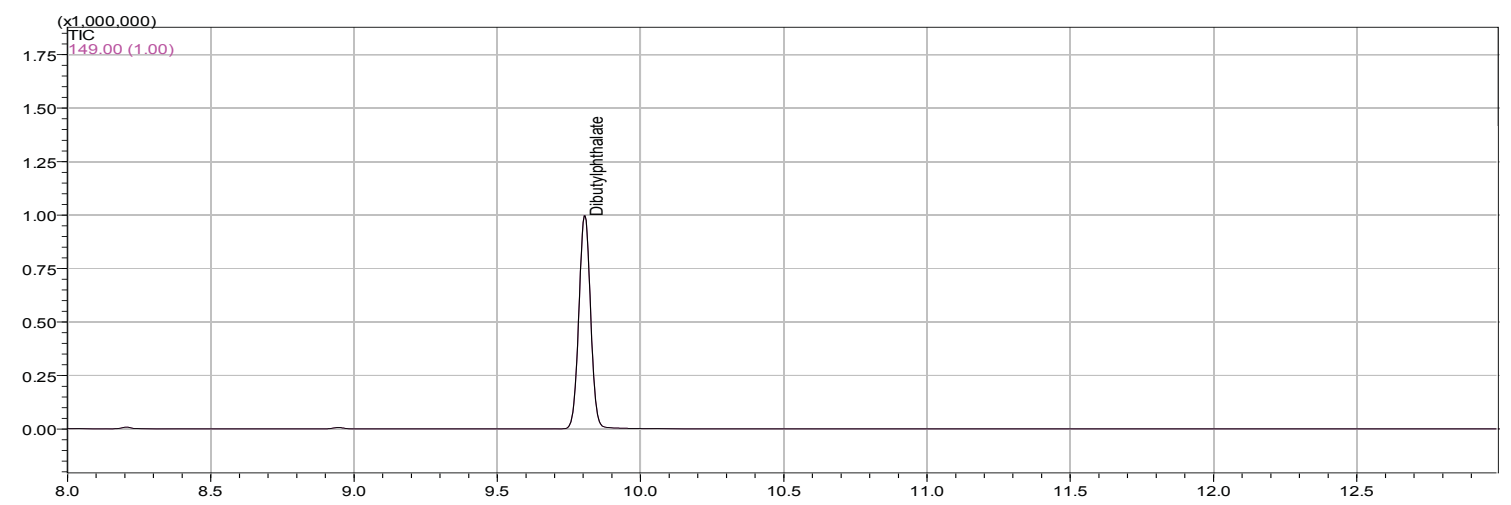

Fig.1. Chromatogram of an extract of a DBP standard solution with concentration $0,10 \mathrm{mg} / \mathrm{dm}^{3}$

For the analysis of strong alcoholic beverages calibration solutions of DBP were prepared on the basis of $40 \%$ water-alcohol mixture with the addition of a solution of aldrin (IS). 


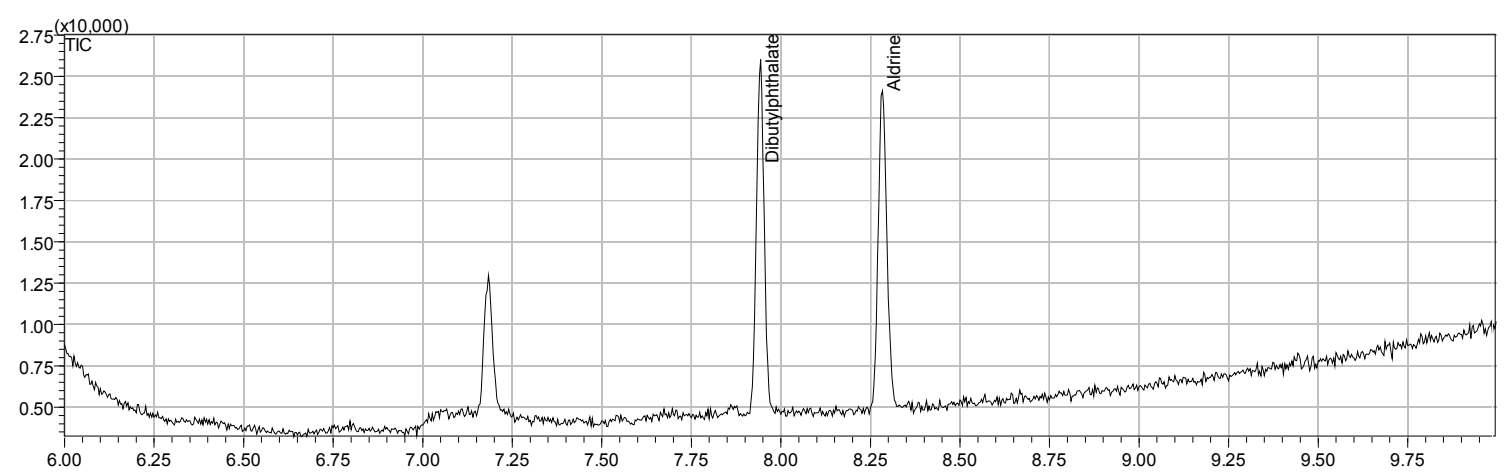

Fig.2. Chromatogram of standard solution of DBP $\left(0,25 \mathrm{mg} / \mathrm{dm}^{3}\right)$ - Aldrin $0,50 \mathrm{mg} / \mathrm{dm}^{3}$

\section{Results and discussion}

The studies conducted in the laboratory of National Center for Quality Testing of the Alcoholic Beverages (Republic of Moldova) included more than 2000 samples of the bottled wine and base-wine for the presence of DBP. The results are shown in table 3 .

Distribution levels of contamination by DBP in wine production (for base-wine, treated wine and bottled wine)

\begin{tabular}{|c|c|c|c|c|}
\hline \multirow{2}{*}{ Product type } & \multicolumn{4}{|c|}{ DBP concentration, $\mathrm{mg} / \mathrm{dm}^{3}(\mathrm{P}=\mathbf{0 , 9 5})$} \\
\hline & $<0,01$ & $\begin{array}{l}\text { 0,01-0,20/ } \\
\text { average }^{1}\end{array}$ & $\begin{array}{l}\text { 0,20-0,30/ } \\
\text { average }^{2}\end{array}$ & $\begin{array}{c}>0,30 / \\
\text { average }^{3}\end{array}$ \\
\hline Base-wine: & $\begin{array}{l}29 \% \\
16 \%\end{array}$ & $\begin{array}{l}\mathbf{4 9 \%} / 0,09 \pm 0,04 \\
\mathbf{6 4 \%} \% 0,12 \pm 0,02\end{array}$ & $\begin{array}{l}\mathbf{1 3 \%} / 0,23 \pm 0,03 \\
\mathbf{1 5 \%} / 0,25 \pm 0,04\end{array}$ & $\begin{array}{l}\mathbf{9 \% /} \quad 0,34 \pm 0,07 \\
\mathbf{5 \% /} \quad 0,39 \pm 0,11\end{array}$ \\
\hline Treated wine: & $\begin{array}{c}9 \% \\
17 \%\end{array}$ & $\begin{array}{l}\mathbf{6 6 \%} / 0,11 \pm 0,07 \\
\mathbf{5 7 \%} / 0,17 \pm 0,05\end{array}$ & 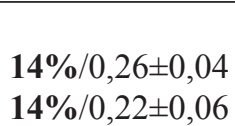 & $\begin{array}{l}\mathbf{1 1 \%} / 0,32 \pm 0,05 \\
\mathbf{1 2 \%} / 0.41 \pm 0,07\end{array}$ \\
\hline Bottled wine: & $\begin{array}{l}19 \% \\
16 \%\end{array}$ & $\begin{array}{l}\mathbf{7 0 \%} / 0,16 \pm 0,05 \\
\mathbf{6 8 \%} / 0,13 \pm 0,06\end{array}$ & $\begin{array}{c}\mathbf{9 \%} / 0,22 \pm 0,06 \\
\mathbf{1 0 \%} / 0,27 \pm 0,05\end{array}$ & $\begin{array}{l}\mathbf{2 \%} / 0,34 \pm 0,07 \\
\mathbf{6 \%} / 0,37 \pm 0,03\end{array}$ \\
\hline
\end{tabular}

$I_{-}<0,01$ - according to the document Hygienic Normatives 2.3.3.972-00 "MCL (Maximum Concentration Limit) of chemicals released from materials, which are in contact with food";

${ }^{2}-<0.20$, according to the requirements of Hygienic Normatives 2.1.5.1315-03 and changes of Hygienic Normatives 2.1.5.228007 "MCL (Maximum Concentration Limit) of chemicals in drinking water, water bodies and cultural-domestic water", for drinking water;

3 - in accordance with Article 11 of Regulation (CE) 882/2004, LMS = 0,3 mg DBP/kg for the model solutions.

To establish the sources of DBP pollution in wines there were studied 7 samples of sulfitated and concentrated must: $<0.01-0.15 \mathrm{ppm}$ of DBP was detected. The lowest concentration level of DBP was characteristic for sulfitated must, then concentrated $-0.05-0.15 \mathrm{ppm}$. The results of investigations of 15 grapes samples were negative. In addition, was investigated water at the five wineries used in wine production. It was found that concentration of DBP in natural water is lower than LOQ, while content in flushing water is $0.04-0.05 \mathrm{ppm}$, and $0.09-0.11 \mathrm{ppm}$ of DBP in softened water.

Therefore contamination of phthalates has a technogenic character, and it is the result of contact with polymeric materials. In the sequel, we studied samples of different materials, which were in contact with wine production during the winemaking process and storage, such as paints, varnishes, primers, pipes, rubber seals. All these tests were conducted according the Directive 2007/19/EG. Also was investigated migration of DBP to a model solution - $15 \%$ aqueous ethanol solution, acidified with tartaric acid. Migration of phthalates from materials, which are in contact with wine, is a continuous process that can continue throughout the period of production or storage. The rate of migration was determined basing on these investigations. Studies have been conducted on materials submitted by Moldovan winemakers and distributors. In addition to fresh paint (intended for contact with food) were analyzed paints, which were in contact with wine during a certain period of time. Fresh (liquid) paint was applied to the flask's inner surface, dried on air in 2-3 days, and then a 
model solution was placed into the flask. Content of DBP was determined in the model solution, which was in contact with the dry polymer within 1 day. Ratio of polymer and model was 1:100. Migration took place at the room temperature $\left(20-22^{\circ} \mathrm{C}\right)$. The results are presented in tab.4.

Table 4

Migration rate of DBP from the polymer (The ratio of polymer: model $=1: 100$ )

\begin{tabular}{|c|c|c|c|}
\hline Migration & Paint & Plastic tubes & Rubber seals \\
\hline 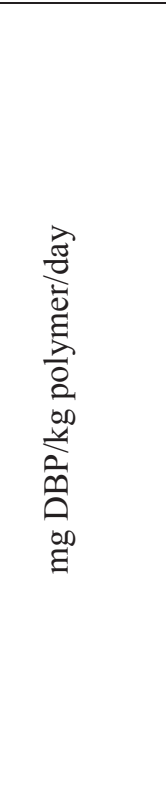 & $\begin{array}{c}\text { Fresh paint } \\
867,4^{1} \\
345^{2} \\
339^{3} \\
\text { Paint contacted with alcoholic beverage } \\
\text { during } ~ 1 \text { year } \\
65,7^{4} \\
63,3^{5} \\
63,7^{6} \\
61,2^{7} \\
\text { Paint contacted with alcoholic beverage } \\
\text { during } 2-3 \text { years } \\
33,2^{8} \\
35,1^{9} \\
\text { Paint contacted with alcoholic beverage } \\
\text { during }>5 \text { years } \\
0,7^{10} \\
3,4^{11} \\
6,9^{12}\end{array}$ & $\begin{array}{c}\text { Non-used in the making } \\
\text { process } \\
142^{13} \\
\text { have been in contact with } \\
\text { product } \\
33,5^{14}\end{array}$ & $\begin{array}{l}\text { Non-used in the making } \\
\text { process } \\
506^{15} \\
\text { have been in contact with } \\
\text { product } \\
31,5^{16}\end{array}$ \\
\hline
\end{tabular}

-16 - materials obtained from various wineries, average of two parallel measurements.

In order to optimize the extraction process of DBP during presampling were investigated some dependencies:

a) Effect of $\mathrm{pH}$ on the level of recovery was established. Samples of synthetic wine with different values of $\mathrm{pH}$ $(3.5,4.0,4.5,5.0,5.5,6.0,6.5,7.0)$ were contaminated by DBP. The level of recuperation for a solution with $\mathrm{pH}=7.0$ was taken as $100 \%$. The results are expressed in fig. 3 .

b) Similarly, the influence of sugar content on the extractability of DBP was investigated with Synthetic wine (2.1). Sugar concentration in the samples was formed using concentrated must $\left(\mathrm{C}(\mathrm{DBP})<0.01 \mathrm{mg} / \mathrm{dm}^{3}\right)$. DBP was added to the obtained model solutions with concentrations of sugars: $0,30,50,100$ and $150 \mathrm{~g} / \mathrm{dm}^{3}$. Chloroform extracts of these samples were analyzed. The results are expressed in fig. 3 .
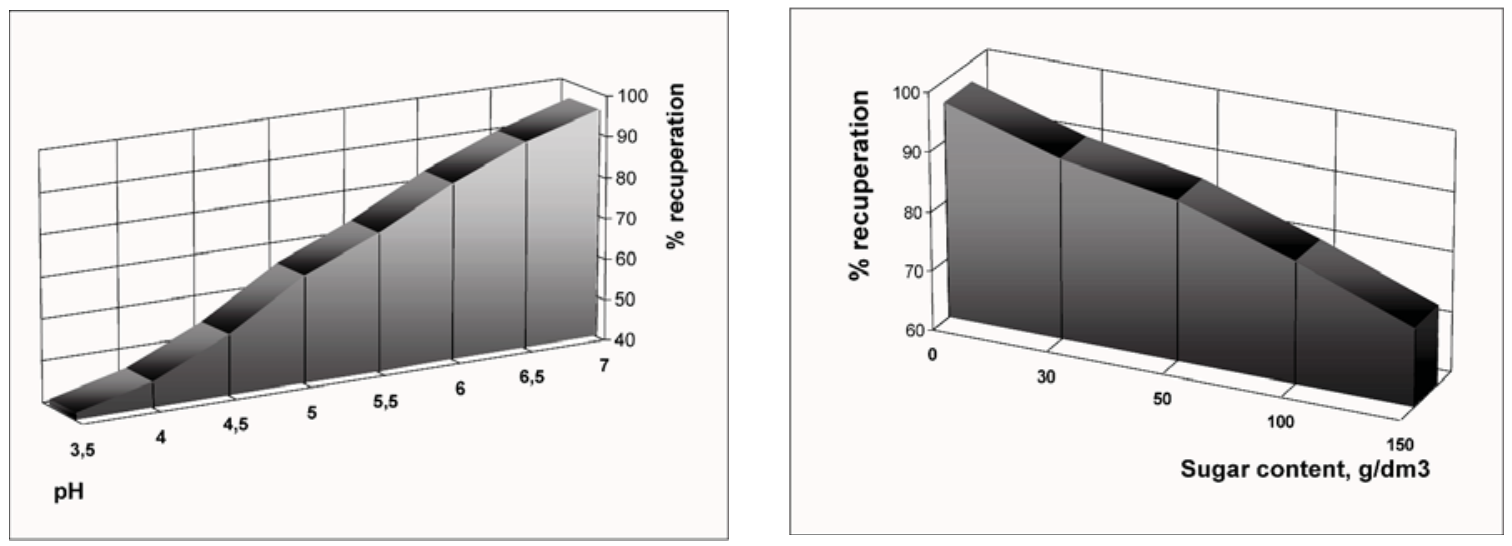

Fig.3. Effect of $\mathrm{pH}$ and sugar's content on the recuperation level of DBP

c) Effect of alcohol content on the extractability of DBP was also investigated using synthetic wine (2.1). Alcohol content in the samples was formed by ethyl alcohol (C (DBP) $<0.01 \mathrm{mg} / \mathrm{dm}^{3}$ ). DBP was added to the obtained model solutions with concentrations of alcohol: 6, 9, 12, 15, 18 and 21\% v/v. Chloroform extracts of these samples were tested. As it follows from the results of investigation alcohol content doesn't influence significantly on the level of recovery (fig. 4). 


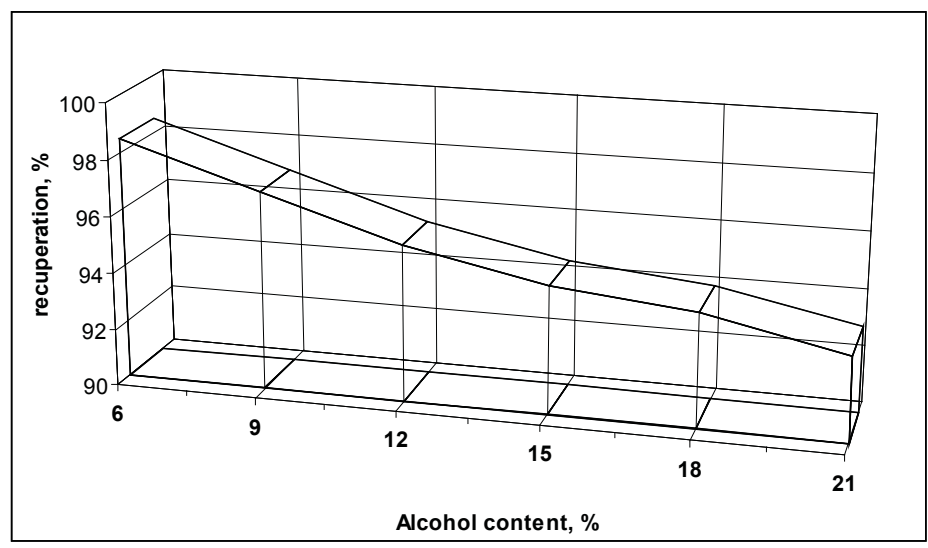

Fig. 4. Effect of alcohol content on the recuperation level of DBP

\section{Conclusions}

In the context of studies conducted in the laboratory of National Center for Quality Testing of the Alcoholic Beverages (Republic of Moldova) were included more than 2000 samples of the bottled wine and base-wine for the presence of most widespread and toxic phthalate - dibutylphthalate. Results display presences DBP in $85 \%$ of studied samples of wines, i.e. a content of DBP more than LOQ $\left(0.01 \mathrm{mg} / \mathrm{dm}^{3}\right)$. Samples of sulfitated and concentrated must, natural and softened water and grapes samples were studied to establish the sources of DBP pollution in wines. Has been determined that contamination of phthalates has a technogenic character, and it is the result of contact with polymeric materials. Optimum conditions of extraction DBP from liquid samples were obtained. Also has been established, that significant influence on extractability is performed by $\mathrm{pH}$ value and sugars content value, the alcohol contents in synthetic wine has not displayed significant effect. In addition migration DBP from polymeric materials has been learnt. In the nearest future we plan to research plugs and other materials used in winemaking process on presence of DBP and its migration.

\section{Acknowledgments}

Authors would like to acknowledge Moldavian wineries and distributors for the represented samples and the required information.

\section{References}

[1]. Peakall DB. Phthalate esters: occurrence and biological effects. Residue Rev 1975, 54: $1-41$.

[2]. WHO 1992: Diethylhexyl phthalate, Environmental Health Criteria 131.

[3]. Phthalates and Their Alternatives:Health and Environmental Concerns. Universisty of Massachusetts Lowell. 2011, 4 .

[4]. CE : The Scientific Committee on Medicinal Products and Medical Devices : Opinion on Medical Devices Containing DEHP Plasticised PVC.

[5]. EU RA DBP 2004.

[6]. Communication 2006/C 90/04 du 13 avril 2006 de la commission européenne.

[7]. CE JRC Institut of health and Consumer protection Toxicology and chemical substance. Phthalates Risk assessment report -2008 .

[8]. CEHRH. Center for the Evaluation of Risks to Human Reproduction. NTPCERHR expert panel.

[9]. CSTEE. Scientific Committee on Toxicity, Ecotoxicity and the Environment. Opinion on the results of a second risk assessment of phthalates in human health part. Brussels: European Commission, 2004.

[10]. T. Lovekamp-Swan, B.J. Davis, Environ. Health Perspect. 111 (2003) 139.

[11]. Caroline Sablayrolles, Mireille Montr'ejaud-Vignoles, David Benanou, Lucie Patria, Michel Treilhou. Development and validation of methods for the trace determination of phthalates in sludge and vegetables. Journal of Chromatography A, 1072 (2005) 233-242.

[12]. Barnabé S, Beauchesne I, Cooper DG, Nicell JA. Plasticizers and their degradation products in the process streams of a large urban physicochemical sewage treatment plant. Water Res 2008, 42: 153- 162. 